\title{
Secondary Multimodal Discourse of the Modern English Mass Culture as a Phenomenon of the Convergence Culture
}

\section{Вторинний мультимодальний дискурс сучасної англомовної маскультури як феномен культури конвергенції}

Mariia Kuznetsova

Ph.D. in Philology,

Assistant Professor
Марія Кузнецова

кандидат філологічних наук, доцент

\section{E-mail: kuznetsovamariaalexandrovna@gmail.com orcid.org/0000-0002-3948-0553}

SHEE «Zaporizhzhia National Technical University», Theory and Practice of Translation Department

$\triangle 64$, Zhukovskogo Str., Zaporizhzhia, Ukraine, 69063
ДВНЗ «Запорізький національний технічний університет», кафедра теорії та практики перекладу

$\triangle$ вул. Жуковського, 64, м. Запоріжжя, Україна, 69063

Original manuscript received April 27, 2018

Revised manuscript accepted January 09, 2019

\begin{abstract}
The article focuses on psycholinguistic features of the secondary multimodal discourse of the modern English mass culture as a linguistic, social and cultural phenomenon and a specific type of communication with a peculiar context. This research paper represents the unique and valid definition of the secondary type discourse, its role, and place as the phenomenon of the convergence culture in the modern English youth subculture.

Based on the differentiation of such related concepts as "youth subculture» and "interpretative community" the research proves that the latter concept is a structural element of a fan subculture. Both of these two concepts model the environment of
\end{abstract}


Secondary Multimodal Discourse of the Modern English Mass...

the secondary textual spaces arranging. The focus of the paper concerns the creation of interpretative communities based on large-scale transmedia projects. The latter develop narration to transfer the world or the project story to the recipient from various perspectives and in different forms.

Another concern of the study is that development and expansion project platforms can go far beyond technical means of information creation and transfer. Transmedia project can concentrate on the primary literary source, TV series, a computer game, and different related products thus anyway contributing to the representation of the whole story. Therefore, this psycholinguistic study focuses on a large-scale factual material the Marvel Universe with its elements represented on various platforms. In combination, these elements create a cohesive plot and a compositional space.

Based on the sociolinguistic experiment results (questionnaires of totally 100 English native speakers), it is claimed that an integrative condition of the Marvel Universe transmedia storytelling is the independence of each separate platform. The main findings of this research cede on the statistical data, the results of onlinequestionnaires, and show that only $15 \%$ of the respondents are acquainted with the part of the Universe represented in comics. $80 \%$ of the respondents believe that movies are the starting point for the Universe entering and thus they are perceived as independent works. Only 5\% of the respondents expressed their uncertainty about the priority of one or another platform.

Another finding is that transmedia storytelling and participatory culture are two key features of convergence culture. The recipients of such large-scale projects lose the status of passive consumers and within the interpretative communities, they become producers of a new media content. Thus, we identify the psycholinguistic mechanism of the modern English mass culture secondary textual spaces arranging through the dominant features of a new cultural paradigm, such as an active development of participatory culture, intertextuality, multimodality, and transmedia storytelling.

In the social and discoursive space of the youth subculture, the recipients borrow any idea, image, plot or a character from the cult textual space, convert them into diverse media formats, and expand them across all available platforms. Thus, the recipients create the unified and inseparable secondary multimodal textual space.

Key words: discourse, multimodality, text, mass culture, media convergence, participatory culture, transmedia storytelling.

\section{Вступ}

Середньостатистична людина XXI ст. за добу опановує такий обсяг інформації, який наші пращури навіть не бачили за роки життя. I це не дивно, адже на часі людство стає цілковитим заручником мобільного зв'язку, смс- та Інтернет-текстінгу. Серйозні 
відмінності у способі життя сучасного соціуму в цілому i способах і форматах його комунікації зокрема слід пов'язувати із потужним розвитком інформаційного суспільства та активізацією медіаконвергенції, що передбачає стрімке проникнення технологій в усі сфери життя і активний процес обміну як вербальною, так i невербальною інформацією, а також дигіталізацію культури i злиття різних медіа.

Останнім часом, як слушно зауважує В.М. Бєрєзін, досить високим $\epsilon$ рівень інтегрованості усіх зображальних засобів, так само як i інших знакових утворень, в єдиний текстуальний простір друкованих і електронних видань (Березин, 2003: 162), а «пошук способів оптимальної подачі інформації призводить до свого роду вибуху візуальних практик, в яких візуальний образ домінує над вербальними способами передачі інформації» (Гончар, 2015: 62). Саме тому наповненість сучасного інформаційного простору медіатекстами, у яких «зображення вже не просто ілюструє вербальний текст, а входить у його семантику» (Пойманова, 1997: 14), вкаузує потребу у дослідженні процесів текстової перцепції, стратегій аранжування, а також способів і засобів когнітивно-комунікативного моделювання текстової складової різноманітних типів дискурсу, які сприяють продуктивному існуванню реципієнта у подібному інформаційному полі. Пасивне споживання інформації більше не є ключовою рисою людства XXI століття, адже на теренах сучасного медіапростору його залучено у безпосередні процеси виробництва і розповсюдження медіа-контенту.

Тим не менш, не слід забувати, що в основі будь-яких комунікаційних процесів незмінно лежить текст, як вища одиниця спілкування на знаковому рівні, яка «організовує нашу діяльність i регулює соціальні відносини між суб'єктами мовленнєвої діяльності» (Дридзе, 1976). Отже, разом із тенденціями впровадження мультимедійних технологій в усі сфери життя сучасної людини спостерігається сплеск дослідницького інтересу до текстів гетерогенної перцептивної i семіотичної природи. Таким чином, актуальність теми представленого дослідження, по-перше, зумовлена зміною погляду на поняття «текст» як об'єкт психолінгвістичних досліджень, адже його (текст) починають аналізувати як семіотично гетерогенний об'єкт, що продукується 3 
Secondary Multimodal Discourse of the Modern English Mass...

використанням елементів вербального коду разом із невербальними засобами комунікації.

По-друге, релевантність поданої наукової розвідки пояснюється перманентно зростаючим інтересом до вивчення тексту / дискурсу з точки зору його мультимодального сприйняття, тобто через одночасну актуалізацію кількох перцептивних каналів. Подібний напрям дослідження, що передбачає вивчення комунікації в іiі природному стані без обмежень щодо іiі режимів, виник ще наприкінці 80-х років XX століття і сьогодні в наукових колах детермінується як мультимодальні дослідження (multimodal studies). Основними розробниками мультимодалістики вважають таких світових лінгвістів, як Т. ван Ліівен (Leeuwen, 2004), Г. Кресс (Kress, 2001, 2006, 2010) і Ч. Фосвіл (Forceville, 2009). Крім того, неабиякий внесок у розробку теоретико-методологічної бази мультимодальних досліджень загалом i питань мультимодального дискурсу зокрема свого часу зробили і всесвітньовідомі психологи i психолінгвісти, зокрема Р. Арнхейм (Arnheim, 1966), Ф. Бартлет (Bartlett, 1995), М. Бортолусі і П. Діксон (Bortolussi \& Dixon, 2003), Дж. Гібсон (Gibson, 1951), Дж. Лакофф i M. Джонсон (Lakoff \& Johnson, 2003), Д. Норман (Norman, 1972) та інші.

Отже, мультимодальний дискурс (multimodal discourse) в останні десятиліття все частіше стає предметом аналізу у зарубіжних працях як лінгвістичного (Daly \& Unsworth, 2011; Iedema, 2007; Jewitt, Bezemer \& O'Halloran, 2016; O’Halloran \& Smith, 2011), так i психолінгвістичного профілю (Chan, Wong \& Wong, 2018; Nicoladis, Marentette \& Navarro, 2016; Reinwein, 2012). Крім того, на сучасному етапі розвитку наукової думки наявні також і поодинокі вітчизняні розвідки, присвячені зокрема вивченню конкуренції модальностей при сприйнятті полімодальних текстів, а саме порівнянню обсягу засвоюваної інформації кінотексту за допомогою вербальної, візуальної та аудіальної «доріжок» (Кибрик, 2010), аналізу когнітивних особливостей сприйняття текстів музичної комунікації, зокрема відеокліпів (Шарифуллин, 2013), аналізу особливостей впливу на динаміку віртуальної комунікації в Інтернеті полікодових текстів і вивченню ролі останніх у самопрезентації учасників Інтернет-спільнот (Мичурин, 2013), а також опису особливостей семіотично ускладнених текстів 3МІ (Мардиева, 2014). 
Вторинний мультимодальний дискурс сучасної англомовної...

Метою цієї статті $€$ дослідження психолінгвістичних особливостей феномену вторинного мультимодального дискурсу сучасної англомовної маскультури у контексті культури конвергенції. Задля досягнення поставленої мети слід вирішити наступні завдання: 1) розглянути культуру конвергенції як нову культурну парадигму, яка визначає взаємозв'язок різних медіа, та розкрити такі іiі ключові поняття, як «культура співучасті» і «трансмедійна розповідь», домінантні принципи яких i становлять основу аранжування вторинного мультимодального дискурсу сучасної англомовної маскультури; 2) здійснити категорійне і статусне розмежування понять «молодіжна субкультура» та «інтерпретативна спільнота», які в межах нової культурної парадигми отримують статус середовища конструювання вторинного типу дискурсу; 3) проаналізувати роль реципієнта англомовних текстів маскультури $a k a$ продуцента вторинних текстів як антропоцентрів матриці вторинного мультимодального дискурсу сучасної англомовної масової культури.

Перш ніж перейти до методів дослідження, що імплементовано у роботі для вивчення вторинного мультимодального дискурсу сучасної англомовної масової культури як феномена культури конвергенції, слід звернути увагу на термінологію методологічного апарату. Так, феномен «вторинного дискурсу сучасної англомовної маскультури» детерміновано як специфічну мисленнєвомовленнєву практику у сучасному англомовному кіберпросторі (див. Кузнецова, 2015), яка передбачає обмін інформацією, ідеями, досвідом, почуттями та емоціями щодо реалій певного культового тексту, який сприймається в межах інтерпретативної спільноти, сформованої його реципієнтами, як прецедентний, та відображає вплив членів цієї спільноти один на одного. Поняттєвим аналогом «вторинного дискурсу» у дослідженні виступає «вториннии текстопростір», і він розпочинається там, де з'являються нові, додаткові смисли, відмінні від буквального розуміння культового тексту. Вторинний дискурс сучасної англомовної масової культури репрезентує себе за допомогою декількох модальностей, оскільки його конститутивні одиниці, вторинні тексти, побудовано, як правило, за допомогою різних семіотичних систем.

Емпіричним матеріалом дослідження, який вдало поєднує візуальні та аудіальні елементи, що відображають різні модальності, 
обрано Bсесвіт Marvel (англ. Marvel Universe) - вигаданий всесвіт, елементи якого розподілені між різними медіаплатформами і разом створюють цілісний сюжетно-композиційний простір. Кожен медіум (серія супергеройських фільмів, серіали, анімаційні фільми, комікси компанії Marvel, мультсеріали, комп'ютерні ігри та інша супутня продукція (іграшки, футболки, кепки, рюкзаки / сумки і т.д.)) робить свій власний унікальний внесок у розкриття історії, що розповідається.

\section{Методи і методики дослідження}

У ході дослідження феномену вторинного мультимодального дискурсу сучасної англомовної маскультури у контексті культури конвергенції імплементується поєднання таких загальнонаукових методів, як: аналіз і синтез, які становлять основу теоретичної бази дослідження, i в межах якої здійснено аналіз праць лінгвістичного та психолінгвістичного профілю вітчизняних i зарубіжних вчених з представленої теми; описовий метод, що поєднує прийоми спостереження, зіставлення, інтерпретації та класифікації теоретичного матеріалу дослідження. Для аналізу специфіки взаємозв'язку різних семіотичних модусів у вторинному мультимодальному дискурсі сучасної англомовної масової культури задіяно системно-функиіональний і компаративний методи.

Крім того, для того, щоб бути найбільш наближеними до отримання об'єктивних даних, ми послугувалися соиіолінгвістичним експериментом як методом, який основано на здійсненні емпіричних досліджень, що підтверджують теоретичні припущення. Так, шляхом online-анкетування, яке було розміщено у базі автоматизованих електронних текстових архівів Archive of Our Own (сайт - https://archiveofourown.org), було опитано носіїв англійської мови, загальною кількістю 100 осіб. Метою експерименту було встановлення рівня обізнаності як прихильників Bсесвіту Marvel, а також членів фандомних спільнот, так і пересічних реципієнтів у вигаданому всесвіті.

Анкета під назвою «The Marvel Universe Quiz» нараховувала 40 питань, які стосувалися як кінематографічного Всесвіту Marvel, так і Всесвіту, який репрезентовано виключно у коміксах. Усі 
Вторинний мультимодальний дискурс сучасної англомовної...

питання анкети було розподілено за трьома категоріями: перша категорія питань стосувалася персонажів і різноманітних реалій усього Всесвіту Marvel, незалежно від платформи його подання, i передбачала лише одну вірну відповідь респондента; друга категорія питань була розрахована на власні відповіді респондентів на питання, які так само стосувалися реалій і персонажів усього Всесвіту; і третя категорія, яка більшою мірою нараховувала питання, що стосувалися кінематографічного всесвіту, була націлена на знання цзитат, взятих зі Всесвіту Marvel, які сьогодні отримали статус прецедентних.

Отже, анкета містила як відкриті питання (30\% від загальної кількості), тобто такі, що не мали варіантів відповідей, а тому не містили підказок i не нав'язували респонденту варіант відповіді, так і закриті (70\% від загальної кількості), коли опитувані мали можливість вибрати один вірний варіант відповіді iз запропонованих нами. 3 одного боку, відкриті питання дали можливість респондентам вільно висловити свою думку у всій повноті і до найдрібніших подробиць. Крім того, в окремій графі анкети респондентам необхідно було зазначити, чи вважають вони себе справжніми прихильниками (фанатами) Bсесвіту Marvel.

Отже, як свідчать результати опитування, на відкриті питання відповідали лише ті респонденти, які мали чітке уявлення про тему опитування, тобто затяті прихильники усього Bсесвіту Marvel. Якщо ж предмет опитування був малознайомий або незвичний, то респонденти ухилялися від відповідей або відповідали не по суті. Тому, на наш погляд, за допомогою відкритих питань нам не вдалося зібрати багату за змістом інформацію. Використання ж закритої форми питання допомогло навіть пересічному респонденту зорієнтуватися у предметі опитування і висловити своє ставлення через набір можливих суджень або оцінок.

Шляхом узагальнення відповідей 3 усіх заповнених анкет $(100 \%)$ було одержано об'єктивну інформацію про ознайомленість носіїв англійської мови зі Всесвітом Marvel, який репрезентовано у коміксах і кіно, зокрема:

- $15 \%$ респондентів продемонстрували обізнаність у Всесвіті, який репрезентовано у коміксах;

- $80 \%$ опитуваних віддали перевагу Кіновсесвіту Marvel; 
Secondary Multimodal Discourse of the Modern English Mass...

- 5\% респондентів висловили невпевненість щодо первинності тієї чи іншої платформи, оскільки не вважають себе справжніми прихильниками Bсесвіту Marvel.

Загалом, результати проведенного online-анкетування видаються иілком інноваційними, оскільки як у вітчизняній, так і у світовій лінгвістиці відсутні дослідження, які присвячено вивченню параметрів когнітивного аранжування вторинного мультимодального текстопростору Всесвіту Marvel, а відтак, i прототипових когнітивних моделей його рецепції.

\section{Результати дослідження}

Культура конвергенції, яку вперше найбільш повно було описано у книзі Генрі Дженкінса «Convergence Culture: Where Old and New Media Collide» (Jenkins, 2006), являє собою зміну відношення громадськості до медіа. Іншими словами, результатом посилення інтерактивних можливостей зв'язку цифрових та Інтернет-технологій стало те, що молоде покоління більше не відчуває себе пасивним споживачем, а прагне бути виробником, активним і творчим учасником культури. Однак, слід пам'ятати, що основним принципом, який скеровує усю фанатську діяльність, $€$ так званий гедоністичний принцип, оскільки уся продукція прихильників масової культури характеризується некомерційною спрямованістю, тобто створюється не для отримання прибутку, а виключно задля творчої самореалізації.

Ксенія Прасолова у кандидатській дисертації (Прасолова, 2009), репрезентуючи доволі змістовний аналітичний екскурс в історію фанатських досліджень, пропонує виділяти три специфічні особливості культури конвергенції, зокрема: розвиток культури співучасті; фрактальність, тобто самоподібність, фанатської творчості; i трансмедійну природу медіа-контенту (Прасолова, 2009), тобто його поширення на різних медійних платформах. Далі пропонуємо детально розглянути зазначені риси культури конвергенції у сув'язі зі вторинним дискурсом як іiі специфічним явищем і лінгвокультурною практикою.

Культура співучасті (participatory culture) полягає у зміні рольових парадигм i у активній соціальній взаємодії. Вона 
передбачає, що реципієнт медіа-контенту стає продуцентом нового корпусу текстів, а межа між автором і читачем, творцем i споживачем зникає. Ця здатність масової аудиторії продукувати власний контент дозволила вивести розвиток наративу на новий рівень - горизонтальний, коли автору вже не належить повністю його історія, а кожен реципієнт вільний ऑiі інтерпретувати i змінювати на свій лад (Delwiche, 2012: 2). Друга риса культури конвергенції, фрактальність, яскраво проявляється в тому, що кожен вторинний текст являє собою, по-перше, інтерпретацію первинного тексту, або культового тексту, а по-друге, довільну кількість інших вторинних текстів (Кузнецова, 2015: 127). Будь-яка фанатська творчість є спробою інтерпретувати культовий текст і одночасно вступити в діалог як з ним, так і $з$ іншими текстовооформленими інтерпретаціями у межах спільноти. При цьому рівнозначними видаються як фанатські наративи, так і метаміркування.

Для назви процесу, в якому частини історії розподілено по різних медіаплатформах, британським філософом і культурологом, Г. Дженкінсом, у науковий обіг було введено поняття «трансмедійна розповідь» (transmedia storytelling). Під цим терміном професор Массачусетського технологічного інституту пропонує розуміти процес створення таких тематичних циклів, які складаються 3 нескінченної низки відносно самостійних фрагментів, об'єднаних єдиним «Всесвітом», які у свою чергу створюються і поширюються за допомогою різних інформаційно-комунікаційних технологій (медіа) і засобів, що не відносяться до ІКТ (Jenkins, 2006: 105). При цьому весь наратив вторинного текстопростору спроектовано таким чином, аби допускати нову інформацію про героїв або введення абсолютно нових персонажів і новий розвиток сюжету.

Сучасна англомовна масова культура пропонує більше сотні трансмедійніх проектів, які, як правило, грунтуються на якомусь літературному першоджерелі i далі отримують різні доповнення i зазнають розширення Всесвіту. Так, фільми кінематографічного Bcесвіту Marvel (англ. Marvel Cinematic Universe) об'єднують разом безліч героїв із різних фільмів, які, однак, засновано на коміксах компанії Marvel і вже пізніше розроблено кінокомпанією Marvel Studios. Наприклад, сюжет «Месників» (англ. Avengers) розгортається впродовж, як мінімум, кілька сот коміксів, шости повнометражних фільмів, декількох серіалів, комп'ютерних i 
рольових ігор і тому подібне. Тим не менш, унаслідок проведеного соціолінгвістичного експерименту виявлено, що саме фільми для більшості споживачів масової культури стають точкою входу у Bceсвіт Marvel i сприймаються ними як самостійні твори. Крім того, на основі здійсненого соціолінгвістичного експерименту анкетування - встановлено, що лише 15\% опитуваних можуть розшифрувати і зрозуміти ті моменти, які представлено виключно у коміксах компанії Marvel.

Вищезазначене констатує, що неодмінною умовою трансмедійної розповіді $\epsilon$ цілісність і самостійність кожної окремої платформи, так само як i можливість водночас бути частиною чогось більшого. Як приклад можна розглянути постійну практику видавництва Marvel 3 випуску комікс-приквелів до кожного свого фільму. Ї̈̈ метою $є$, як правило, спроба посилити інтерес до майбутніх фільмів або репрезентувати ситуації очима інших героїв, наприклад: бій у Нью-Йорку 3 перспективи Локі у приквелі до фільму «Avengers: Age of Ultron». Нещодавно видавництво випустило у двох томах (№ 1 у грудні 2017 р. та № 2 у січні 2018 р.) комікс-приквел «Marvel's Black Panther Prelude» до фільму «Black Panther» (2018), метою якого було зобразити те, що у кіновсесвіті залишиться поза кадром, зокрема історію, яка відбувається за часів, коли королем Ваканди був Т'Чакка (його ми бачили у фільмі «Captain America: Civil War» 2016 р.). Крім того, події у коміксі хронологічно співпадають із фільмом «Iron Man», підтвердженням того є епізод, де Т'Чакка зі своїм сином Т’Чаллой обговорюють вчинок Тоні Старка, який публічно оголосив про те, що Залізна людина є його alter ego.

Більше того, трансмедійна розповідь є зближенням масмедійних платформ i тих платформ, які не $є$ у традиційному розумінні технічними засобами створення і передачі масової інформації. Так, доказом є встановлена у публічній бібліотеці Нортлейк у передмісті Чикаго статуя героя коміксів Marvel Халка або встановлена до 75-до річчя супергероя в Брукліні майже чотирьохметрова статуя Капітана Америки 3 його знаменитим щитом. Подібний трансмедійний наратив робить унікальний внесок кожної платформи (коміксу, фільму, комп'ютерної гри або будь-якої іншої супутньої продукції за мотивами історії Всесвіту) у цілу розповідь. 
Як бачимо, появу нових способів і форматів комунікації, без сумніву, логічно пов'язувати, перш за все, з питанням про буття молодіжних субкультур та інтерпретативних спільнот, адже їх частка в аранжуванні нових мовленнєвих і лінгвокультурних практик є чи не найбільшою у сучасному комунікативному просторі. I це не дивно, адже будь-яка субкультура перманентно впливає на базову культуру суспільства безпосередньо або опосередковано. Як соціальне явище, субкультура виражена системою цінностей і пріоритетів, специфікою суджень і уподобань, способами поведінки певної соціальної групи, що відрізняється від інших культур у суспільстві, але водночас пов'язана з ними (Еремеева, 2011; Петрова, 2010). Власне молодіжна субкультура детермінується у наукових колах як джерело інновацій і відкриттів у певному виді діяльності, як варіант масової культури, продукт медіа-індустрії, як форма творчої активності молодого покоління (Левикова, 2004). Таким чином, існування тієї чи іншої інтерпретативної спільноти безпосередньо пов'язано та обумовлено читацькою / глядацькою діяльністю, в центрі якої знаходиться певний продукт масової культури.

Влучним способом розрізнення цих двох понять «субкультура» та «інтерпретативна спільнота» - видається їх репрезентація у вигляді гіпо-гіперонімічної кореляції «загальнечасткове». Так, інтерпретативні спільноти, які також відомі як фандоми, виступають структурним елементом фанатської субкультури, учасники якої об’єднані єдиним інтересом, пов'язаним iз певним продуктом популярної масової культури. Сучасний англомовний кіберпростір об'єднує молодіжні субкультури та інтерпретативні спільноти по всьому світу. Як правило, будь-яка інтерпретативна спільнота утворюється на базі великого трансмедійного проекту, ядром якого постає творча діяльність iii суб'єктів, саме вона і закладає підвалини всіх похідних видів діяльності, які конструюють вторинні текстопростори масової культури, а саме: фанфікшену (жанр масової літератури, який створюється фанатами за мотивами культового твору), конвенти (з'їзди, зустрічі фанатів), фанзіни (журнали, які видаються в межах фандому), рольові ігри, реконструкції, косплеї (костюмовані ігри), фан-арти тощо.

Таким чином, цільовою аудиторією трансмедійних проектів від самого початку є фанати. Їх роль, як учасників інтерпретативних 
спільнот, у межах вторинного текстопростору полягає у співаторстві, тобто інтерпретації медіа-текстів і продукуванні власного контенту, який вони розповсюджують по медійних платформах, збільшуючи тим самим як обсяг контенту, так i помітність оповідного «Всесвіту» у кіберпросторі. Психологічний настрій реципієнта, його бажання і попередні знання організовують і направляють процеси запам'ятовування і відтворення (Ковшиков \& Глухов, 2007). Безперечно, кожен культовий текст містить певні смислові лакуни, які власне і постають джерелом варіативності його розуміння.

Однією 3 ключових ідей нашого дослідження $\epsilon$ те, що інтерпретатор є активним суб'єктом сприйняття, він активно залучений до породження смислів і створення нового тексту, тобто вторинного тексту, а, отже, його діяльність спрямована як на розшифровку текстового коду, так і на добудовування смислу. Це пояснюється різноманітністю поглядів на одних i тих же персонажів і по-різному інтерпретовані події культового тексту у вторинному текстопросторі. Рецепцію культового тексту в межах інтерпретативних спільнот, слідом за У. Еко, можна порівняти 3 пікніком, на який автор приносить слова, а читач смисл (Эко, 1996: 10-21). Але в той же час «сказати, що інтерпретація потенційно необмежена, не означає, що в неї немає об'єкта і вона існує тільки заради себе самої» (Есо, 1992: 38), адже «подібний спосіб інтерпретування тексту не може привести ні до чого іншого, як до помилкової інтерпретації, коли інтерпретатор довільним чином приписує тексту свої суб’ єктивні смисли» (Есо, 1990: 42).

Культовий текст за таких умов постає континуумом потенційних інтерпретацій, а кожен реципієнт, як активний суб'єкт сприйняття та інтерпретації, знаходить на свій власний смак і вподобання платформу у трансмедійній оповіді. Саме від обраного каналу для інтерпретації і залежить якими семіотичними засобами - модусами, тобто «соціально сформованими, культурно встановленими семіотичними ресурсами продукування значення» (Kress, 2010: 79) - буде користуватись вторинний продуцент для аранжування вторинного текстопростору. Оскільки останнім часом роль візуального компонента все більше зростає порівняно до вербальної складової, то як провідна модальність у вторинному дискурсі виступає візуальна. Отже, «привид Автора з'являється виключно на правах гостя» (Барт, 1994: 420) у вторинному 
мультимодальному тексті. Термін «мультимодальний», таким чином, підкреслює функціонально-інструментальний аспект кодування повідомлення вторинним продуцентом. Серед усього різноманіття способів передачі інформації, окрім статичних i динамічних зображень, як провідні у вторинному мультимодальному текстопросторі виділяємо також звукові ефекти, музику і текст 3 урахуванням його шрифту та оформлення в цілому.

\section{Висновки}

У XXI столітті у зв'язку 3 бурхливим розвитком дискурсивних практик у глобальному комунікативному просторі особливої лінгвістичної уваги потребує активна діяльність молодіжних субкультур, які постають центром конструювання текстових складових різних типів дискурсу. Відтак, актуальним видається психолінгвістичний вектор дослідження прототипових когнітивних моделей рецепції прецедентних текстопросторів сучасної англомовної масової культури і параметрів когнітивного аранжування їх текстових проекцій.

Перманентна ескалація фанатської субкультури прискорила поширення нових трансмедійних проектів, які утворено навколо цілісного вигаданого світу, i які мають певне літературне першоджерело, що належить, як правило, до сучасної масової культури. Одним із таких проектів є Bсесвіт Marvel, який аранжовано у такий спосіб, що реципієнту надається можливість перетворитися на активного учасника процесу породження нових смислів, тобто стати вторинним продуцентом у матриці вторинного текстопростору. Розглянутий у представленій науковій розвідці феномен «вторинного мультимодального дискурсу» разом із іншими аспектами фанатської практики, зокрема виданням власних журналів, розробкою Інтернетсайтів із різноманітною графічною і відеопродукцією, $є$ одним із провідних елементів фанатської субкультури.

Процес аранжування вторинного дискурсу сучасної англомовної маскультури як феномена культури конвергенції базується на гармонійному поєднанні чотирьох фундаментальних принципів: по-перше, активного розвитку культури співучасті; nо-друге, інтертекстуальності; по-третє, мультимодальності i, 
Secondary Multimodal Discourse of the Modern English Mass...

nо-четверте, трансмедійності. Культура співучасті пропагандує нову стратегію взаємодії фанатської аудиторії 3 медіаконтентом, тим самим уможливлює реалізацію творчого потенціалу реципієнтів прецедентного текстопростору шляхом продукування i розповсюдження власного медіаконтенту. Другий принцип фрактальність, або інтертекстуальність, - передбачає навмисне і цілеспрямоване запозичення ключових елементів культового тексту 3 метою продукування нового змісту. Загалом вторинний дискурс має нативний інтертекстуальний характер, оскільки його смисл може бути повною мірою зрозумілий тільки у процесі діалогічної взаємодії первинного (культового) і вторинного текстопросторів. Під мультимодальністю мається на увазі сукупність відчуттів, що надходять шляхом різних модальностей при чуттєвому сприйнятті об'єкта дійсності, у нашому випадку - культувого текстопростору. Термін «модальність» у межах поданого дослідження, таким чином, дефіновано як приналежність до певної сенсорної системи. Останній принцип - трансмедійний наратив вторинного тектопростору передбачає розкриття історії вигаданого світу за допомогою безлічі вторинних текстів, які представляють собою різні точки входу у Всесвіт медіафраншизи Marvel.

Тим не менш, як свідчать результати нашої практичної діяльності, відправною точкою при аранжуванні вторинного англомовного дискурсу досліджуваного нами Всесвіту, все ж таки залишається Кіновсесвіт Marvel (Marvel Cinematic Universe), адже $80 \%$ опитуваних переконані, що саме кінофільми є самостійними продуктами і точкою входу у Всесвіт. Лише 15\% респондентів за результатами online-анкетування ознайомлені 3 тією частиною Bсесвіту, яку репрезентовано у коміксах (Marvel Comics). Це свідчить про те, що вторинними продуцентами запозичуються здебільшого лише персонажі та інші окремі реалії культового текстопростору, а вторинні тексти являють собою, як правило, альтернативну проспекцію або ретроспекцію певних подій, прописування особистих історій окремо взятих персонажів, дослідження їх характерів або навіть породження нових, занурення ïx у заново генеровані ситуації, фокусування на психологічних i емоційних проблемах улюблених персонажів, заповнення лакун у ïx стосунках, зміні середовища існування улюблених персонажів, акцентування уваги на їх плотських стосунках тощо. До останніх 
5\%, як свідчить аналіз анкет, належать пересічні респонденти, які не $\epsilon$ прихильниками культового текстопростору, але які мають певне уявлення про основні персонажі Всесвіту й так чи інакше обізанані в його основних сюжетних лініях.

Отже, вторинний мультимодальний дискурс сучасної англомовної масової культури як феномен культури конвергенції постає своєрідною і унікальною лінгвокультурною практикою, тобто матрицею перетину різних медіаформатів, що дозволяє взаємодіяти різним медіа 3 урахуванням властивих їм технічних можливостей i наративних засобів для створення єдиного текстопростору. Будь-яка ідея, зображення, сюжет, персонаж або подія культового текстопростору, i в залежності від того, прихильниками якої платформи постають вторинні продуценти, шляхом адаптації іншими медіа з урахуванням властивих їм механізмів і правил, конвертуються вторинними авторами у різноманітні медіаформати i поширюються по всім доступним комунікаційним каналам, створюючи єдиний i неподільний вторинний текстопростір Bceсвіту Marvel. Таким чином, досліджений у контексті культури конвергенції вторинний мультимодальний дискурс є підтвердженням впровадження нових креативних форм творчості, що виникають у споживачів сучасної англомовної масової культури.

Перспективу подальших наукових студій вбачаємо у порівняльному аналізі англомовного та україномовного дискурсів сучасної маскультури, зокрема у мультимодальному векторі їх дослідження. 


\section{the W/Th/L universe Quize}

How well do you know the Marvel Universe though?

Choose one variant!

Or give your own answer!

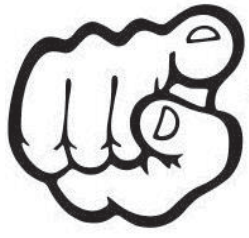

Are you a true Marvel fan?

Yes

No

\begin{tabular}{|c|c|c|}
\hline \begin{tabular}{|l|} 
№ \\
\end{tabular} & Questions & true / false \\
\hline 1 & 2 & 3 \\
\hline \multicolumn{3}{|c|}{ Choose one variant } \\
\hline 1. & $\begin{array}{l}\text { What is the name of Tony Stark's building that the team uses as head-quarters in } \\
\text { Marvel: Ultimate Alliance? } \\
\text { Camp Hammond } \\
\text { Stark Tower } \\
\text { Iron Tower } \\
\text { S.H.I.E.L.D. Headquarters }\end{array}$ & \\
\hline 2. & $\begin{array}{l}\text { Edwin Jarvis is the butler to: } \\
\text { Bruce Wayne } \\
\text { Charles Xavier } \\
\text { Tony Stark } \\
\text { Brian Braddock }\end{array}$ & \\
\hline 3. & $\begin{array}{l}\text { The Fantastic Four have the headquarters in what building? } \\
\text { Stark Tower } \\
\text { Fantastic Headquarters } \\
\text { Baxter Building } \\
\text { Xavier Institute }\end{array}$ & \\
\hline 4. & $\begin{array}{l}\text { Thor has two war goats to pull his chariot. They are named: } \\
\text { Balder and Hermod } \\
\text { Thunder and Lightning } \\
\text { Ask and Embla } \\
\text { Toothgrinder and Toothgnasher }\end{array}$ & \\
\hline
\end{tabular}




\begin{tabular}{|c|c|c|}
\hline 1. & 2. & 3. \\
\hline 5. & $\begin{array}{l}\text { The Mjolnir is a } \\
\text { Shield } \\
\text { Hammer } \\
\text { Suit } \\
\text { Scepter }\end{array}$ & \\
\hline 6. & $\begin{array}{l}\text { The vampire hunter Blade is a: } \\
\text { Mutant } \\
\text { Human } \\
\text { Vampire } \\
\text { Half vampire }\end{array}$ & \\
\hline 7. & $\begin{array}{l}\text { What is commonly believe to be The Black Widow's previous occupation before } \\
\text { becoming a Russian spy? } \\
\text { A ballet dancer } \\
\text { A military pilot } \\
\text { A thief } \\
\text { An athlete }\end{array}$ & \\
\hline 8. & $\begin{array}{l}\text { Ghost Rider is known as: } \\
\text { The Guardian Devil } \\
\text { The Spirit of Hate } \\
\text { The Spirit of Vengeance } \\
\text { The Red Skull }\end{array}$ & \\
\hline 9. & $\begin{array}{l}\text { Who is the first avenger? } \\
\text { Iron Man } \\
\text { Spider Man } \\
\text { Ant Man } \\
\text { Captain America }\end{array}$ & \\
\hline 10 . & $\begin{array}{l}\text { Captain America once faced off against this DC comics superhero: } \\
\text { Wonder Woman } \\
\text { Superman } \\
\text { Batman } \\
\text { Aquaman }\end{array}$ & \\
\hline 11. & $\begin{array}{l}\text { The Vision is an android created by: } \\
\text { Reed Richards } \\
\text { Tony Stark } \\
\text { Ultron } \\
\text { Doctor Doom }\end{array}$ & \\
\hline 12. & $\begin{array}{l}\text { What is Iron Fist's real name? } \\
\text { Daniel Rand } \\
\text { Kai Erwin } \\
\text { Robert Kox } \\
\text { Mr. Bobbastic }\end{array}$ & \\
\hline 13. & $\begin{array}{l}\text { Deadpool joined the Weapon X program because: } \\
\text { He had incurable cancer } \\
\text { He was forced to } \\
\text { He thought it would be fun } \\
\text { He wanted to fight for justice }\end{array}$ & \\
\hline 14. & $\begin{array}{l}\text { What was Wolverine's name when he was a Horseman of Apocalypse? } \\
\text { Rage } \\
\text { Death } \\
\text { Destruction } \\
\text { Oblivion }\end{array}$ & \\
\hline
\end{tabular}


Secondary Multimodal Discourse of the Modern English Mass...

\begin{tabular}{|c|c|c|}
\hline 1. & 2. & 3. \\
\hline 15. & $\begin{array}{l}\text { In the comics Ant Man has the ability to shrink or grow. } \\
\text { True! } \\
\text { False! } \\
\text { Not sure! } \\
\text { Only to shrink! }\end{array}$ & \\
\hline 16. & $\begin{array}{l}\text { The actor that plays Captain America also played ___ in Fantastic } \\
\text { Four: Rise of the Silver Surfer. } \\
\text { Mr. Fantastic } \\
\text { The Thing } \\
\text { Dr. Doom } \\
\text { Human Torch }\end{array}$ & \\
\hline 17. & $\begin{array}{l}\text { Who is the winter soldier? } \\
\text { Captain America } \\
\text { Bucky Barnes } \\
\text { Luke Cage } \\
\text { Peter Parker }\end{array}$ & \\
\hline 18. & $\begin{array}{l}\text { Where does Dr. Strange seek out a cure for his damaged hands? } \\
\text { China } \\
\text { Tibet } \\
\text { Japan } \\
\text { Mongolia }\end{array}$ & \\
\hline 19. & $\begin{array}{l}\text { How old is Thor? } \\
35 \\
100 \\
500 \\
1,000\end{array}$ & \\
\hline 20. & $\begin{array}{l}\text { The comic book version of 'Iron Man' is based on what real-life eccentric? } \\
\text { Warren Beatty } \\
\text { Elon Musk } \\
\text { Teddy Roosevelt } \\
\text { Howard Hughes }\end{array}$ & \\
\hline 21. & $\begin{array}{l}\text { The clawed superhero Wolverine is what nationality? } \\
\text { Canadian } \\
\text { American } \\
\text { Australian } \\
\text { Israeli }\end{array}$ & \\
\hline 22. & $\begin{array}{l}\text { Which female character took on the role of 'Thor' when the original was unable? } \\
\text { Jane Foster } \\
\text { Black Widow } \\
\text { Wonder Woman } \\
\text { Mary Jane }\end{array}$ & \\
\hline 23. & $\begin{array}{l}\text { What allows the Hulk to increase his strength? } \\
\text { Radiation } \\
\text { Spider bites } \\
\text { Rage } \\
\text { Pilates }\end{array}$ & \\
\hline 24. & $\begin{array}{l}\text { Who was first known host of the alien symbiote Venom? } \\
\text { Thor } \\
\text { Spider-Man } \\
\text { Iron Man } \\
\text { Deadpool }\end{array}$ & \\
\hline
\end{tabular}


Вторинний мультимодальний дискурс сучасноӥ англомовної...

\begin{tabular}{|c|c|c|}
\hline 1. & 2. & 3. \\
\hline 25. & $\begin{array}{l}\text { What superhero's healing abilities allows him to donate his organs to help } \\
\text { others? } \\
\text { Wolverine } \\
\text { Thor } \\
\text { Magneto } \\
\text { Deadpool }\end{array}$ & \\
\hline \multicolumn{3}{|c|}{ The $2^{\text {nd }}$ category $\quad$ Give your own answer! } \\
\hline 26. & How many "Infinity Stones" are said to exist in the Marvel Comic Universe? & \\
\hline 27. & $\begin{array}{l}\text { Whom did the comic cover proclaim: "He's here! The world's first and greatest } \\
\text { Canadian superhero!"? }\end{array}$ & \\
\hline 28. & Which MCU movie featured Spider-Man’s first appearance? & \\
\hline 29. & Who played the Hulk before Mark Ruffalo? & \\
\hline 30. & Which war did Captain America fight in? & \\
\hline \multicolumn{3}{|c|}{ The $3^{\text {rd }}$ category Who said this? } \\
\hline 31. & $\begin{array}{l}\text { The strength of this country isn't in buildings of brick and steel. It's in the } \\
\text { hearts of those who have sworn to fight for its freedom! } \\
\ldots \ldots \ldots \ldots \ldots \ldots \ldots \ldots \ldots \ldots \ldots \ldots \ldots \ldots \ldots \ldots \ldots \ldots \ldots \ldots \ldots \ldots \ldots \ldots \ldots \ldots \ldots \ldots \ldots \ldots \ldots \ldots \ldots \ldots \ldots \ldots \ldots \ldots \ldots \ldots \ldots \ldots\end{array}$ & \\
\hline 32. & 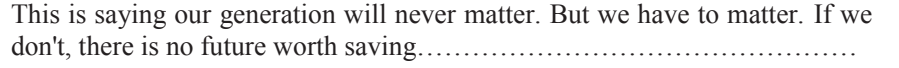 & \\
\hline 33. & 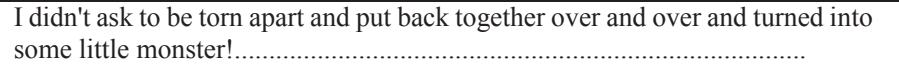 & \\
\hline 34. & 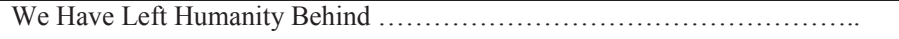 & \\
\hline 35. & 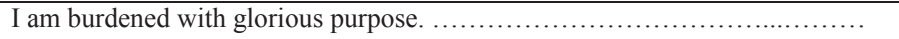 & \\
\hline 36. & 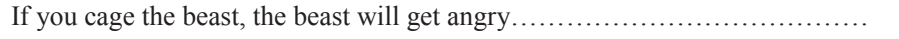 & \\
\hline 37. & I'm Just A Kid From Brooklyn ........ & \\
\hline 38. & 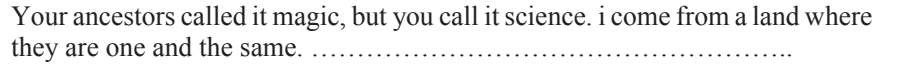 & \\
\hline 39. & 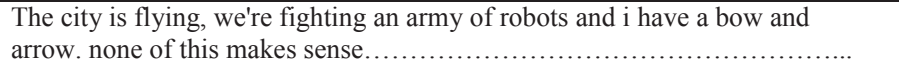 & \\
\hline 40. & 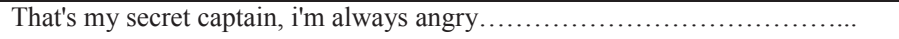 & \\
\hline
\end{tabular}

\section{THANK YOU VERY MUCH!}




\section{Література}

Барт Р. Избранные работы : Семиотика. Поэтика. Москва : Прогресс, 1994. 615 с. Березин В.М. Массовая коммуникация: сущность, каналы, действия. Москва : Изд-во РИП-Холдинг, 2003. 174 с.

Гончар И.А. Вербализация инфографики: специфика текстообразования (на материале видеограмм «Россия в цифрах»). Филологический класс. 2015. № 2. С. 62-65.

Дридзе Т.М. Текст как иерархия коммуникативных программ (информативноцелевой подход). Смысловое восприятие речевого сообщения. Москва : Наука, 1976. С. 48-56.

Еремеева В.Ф. Современная молодежная субкультура: без ценностей. Система ценностей современного обществва. 2011. № 17-2. С. 123-125.

Кибрик А.А. Мультимодальная лингвистика : направления исследований. Когнитивные исследования. Москва, 2010. С. 135-152.

Ковшиков В.А., Глухов В.П. Психолингвистика. Теория речевой деятельности. Москва : Астрель, 2007. 224 с.

Кузнецова М.О. Вторинний дискурс англомовних текстів сучасної масової культури : монографія. Запоріжжя : ЗНТУ, 2015. 202 с.

Левикова С.И. Молодежная субкультура. Москва : ФАИР ПРЕСС, 2004. 381 с.

Мардиева Л.А. Коды визуального поведения и прецедентные визуальные феномены в составе семиотически осложненных текстов средств массовой информации. Политическая лингвистика. 2014. № 2(48). С. 246-250.

Мичурин Д.С. Влияние поликодовых текстов на динамику виртуальной коммуникации в интернете. Гуманитарные, сочиально-экономические $и$ общественные науки. 2013. № 4. С. 290-294.

Петрова Ю.А. К проблеме сущности и типологии субкультур. Гуманитарные $и$ сочиальныле науки. 2010. № 1. С. 30-39.

Пойманова О.В. Семантическое пространство видеовербального текста : дисс. ... канд. филол. наук. Москва, 1997. 237 с.

Прасолова К.А. Фанфикшн: литературный феномен конца XX - начала XXI века : творчество поклонников Дж. К. Ролинг : автореф. дисс. ... канд. філол. наук. Калининград, 2009. 24 с.

Шарифуллин С.Б. Вербально-иконические тексты в современной музыкальной коммуникации : автореф. дисс. ... канд. филол. наук. Красноярск, 2013. 24 с.

Эко У. Два типа интерпретации. Новое литературное обозрение. 1996. № 21. C. $10-21$.

Arnheim, R. (1966). Towards a Psychology of Art. Collected Essays. Los Angeles : University of California.

Bartlett, F. (1995). Remembering: A Study in Experimental and Social Psychology. Cambridge : The University Press. https://doi.org/10.1017/CBO9780511759185

Bortolussi, M., \& Dixon, P. (2003). Pscyhonarratology. Foundations for the Empirical Study of Literary Response. Cambridge : CUP.

Chan, T.K.S., Wong, S.W.L., Wong, A.M.Y., et al. (2018). The Influence of Presentation Format of Story on Narrative Production in Chinese Children Learning English-as-a-Second-Language: A Comparison Between Graphic Novel, Illustration Book and Text. Journal of Psycholinguistic Research, 1-22. https:// doi.org/10.1007/s10936-018-9600-9 
Daly, A., \& Unsworth, L. (2011). Analysis and comprehension of multimodal texts. Australian Journal of Language and Literacy, 34(1), 61-80.

Delwiche, A. (2012). The Participatory Cultures Handbook. New York : Routledge. https://doi.org/10.4324/9780203117927

Eco, U. (1992). Interpretation and Overinterpretation. Cambridge : Cambridge University Press. https://doi.org/10.1017/CBO9780511627408

Eco, U. (1990). Unlimited Semiosis and Drift: Pragmaticism vs. «Pragmatism». The Limits of Interpretation (Advances in Semiotics), (pp. 22-43). Bloomington; Indianapolis : Indiana University Press.

Forceville, C., \& Urios-Aparisi, E. (2009). Multimodal Metaphor. Berlin : Mouton de Gruyter. https://doi.org/10.1515/9783110215366

Gibson, J.J. (1951). The perception of the visual world. Boston : Houghton Mifflin.

Jewitt, C., Bezemer, J., \& O’Halloran, K.L. (2016). Introducing multimodality. London \& New York : Routledge.

Iedema, R. (2007). Multimodality, resemiotization: extending the analysis of discourse as multi-semiotic practice. Visual Communication, 2(1), 29-57. https://doi. org/10.1177/1470357203002001751

Jenkins, H. (2006). Convergence culture: Where old and new media collide. New York and London : NYU press.

Kress, G.R. (2010). Multimodality. A Social Semiotic Approach to Contemporary Communication. London and New York : Routledge.

Kress, G.R., \& Leeuwen, T. van (2001). Multimodal Discourse. Bloomsbury Academic.

Kress, G.R., \& Leeuwen, T. van (2006). Reading Images: The Grammar of Visual Design. London : Routledge. https://doi.org/10.4324/9780203619728

Lakoff, G., \& Johnson, M. (2003). Metaphors We Live by. Chicago : University of Chicago Press. https://doi.org/10.7208/chicago/9780226470993.001.0001

Leeuwen, T. van (2004). Introducing Social Semiotics: An Introductory Textbook. London : Routledge. https://doi.org/10.4324/9780203647028

Nicoladis, E., Marentette, P., \& Navarro, S. (2016). Gesture Frequency Linked Primarily to Story Length in 4-10-Year Old Children's Stories. Journal of Psycholinguistic Research, 45(2), 189-204. https://doi.org/10.1007/s10936-014-9342-2

Norman, D.A. (1972). Memory, Knowledge and Answering of Questions. Contemporary Issues in Cognitive Psychology. The Loyola Symposium. San Diego : University of California.

O’Halloran, K.L., \& Smith, B. (2011). Multimodal Studies: An Emerging Research Field. Multimodal Studies. Exploring Issues and Domain. (pp. 1-16). NY, Abington.

Reinwein, J. (2012). Does the Modality Effect Exist? and if So, Which Modality Effect? Journal of Psycholinguistic Research, 41(1), 1-32. https://doi.org/10.1007/ s10936-011-9180-4

\section{References}

Bart, R. (1994). Izbrannye raboty: Semiotika. Poetika [Selected Works: Semiotics. Poetics]. Moscow : Progress [in Russian].

Berezin, V.M. (2003). Massovaya kommunikatsiya: sushchnost, kanaly, deystviya [Mass communication: essence, channels, actions]. Moscow : Izd-vo RIPHolding [in Russian]. 
Secondary Multimodal Discourse of the Modern English Mass...

Gonchar, I.A. (2015). Verbalizatsiya infografiki: spetsifika tekstoobrazovaniya (na materiale videogramm «Rossiya V tsifrakh») [Infographics verbalization: special features of text formation (based on «russia in numbers» videograms)]. Filologicheskiy klass - Philological class, 2, 62-65 [in Russian].

Dridze, T.M. (1976). Tekst kak ierarkhiya kommunikativnykh programm (informativnotselevoy podkhod) [Text as a hierarchy of communication programs (informativetargeted approach)]. Smyslovoe vospriyatie rechevogo soobscheniya - The sense perception of a speech message, (pp. 48-56). Moscow : Nauka [in Russian].

Eremeeva, V.F. (2011). Sovremennaya molodezhnaya subkultura: bez tsennostey [Modern youth subculture: without values]. Sistema tsennostey sovremennogo obshchestva - The system of values of modern society, 17-2, 123-125 [in Russian].

Kibrik, A.A. (2010). Multimodalnaia lingvistika [Multimodal linguistics]. Kognitivnye issledovaniia - Cognitive researches, (pp. 135-152) [in Russian].

Kovshikov, V.A., \& Glukhov, V.P. (2007). Psikholingvistika. Teoriya rechevoy deyatelnosti [Psycholinguistics. Theory of speech activity]. Moscow : Astrel [in Russian].

Kuznetsova, M.O. (2015). Vtorynnyi dyskurs anglomovnykh tekstiv suchasnoi masovoi kultury [Secondary discourse of English modern mass culture texts]. Zaporizhzhia : ZNTU [in Ukrainian].

Levikova, S.I. (2004). Molodezhnaya subkultura [Youth Subculture]. Moscow : FairPress [in Russian].

Mardieva, L.A. (2014). Kody visualnogo povedeniia i pretsedentnye visualnye fenomeny $\mathrm{v}$ sostave semioticheski oslozhnennykh tekstov sredstv massovoi informatsii [Codes of visual behavior and precedent visual phenomenon in the semiotically complicated mass media texts]. Politicheskaia lingvistika - Political linguistics, 2(48), 246-250 [in Russian].

Michurin, D.S. (2013). Vliianie polikodovyh tekstov na dinamiku virtualnoy kommunikatsii $\mathrm{v}$ internete [Impact of multimodal texts on the virtual Internetbased communication]. Gumanitarnye, sotsialno-ekonomicheskie i obschestvennye nauki - Humanities, socio-economic and social sciences, 4, 290-294 [in Russian].

Petrova, Yu.A. (2010). K probleme sushchnosti i tipologii subkultur [To the problem of the essence and typology of subcultures]. Gumanitarnye $i$ sotsialnye naukiHumanities and Social Sciences, 1, 30-39 [in Russian].

Poymanova, O.V. (1997). Semanticheskoe prostranstvo videoverbalnogo teksta [Semantic space of video-verbal text]. Candidate's thesis. Moscow : Mosk. gos. lingvisticheskii un-t [in Russian].

Prasolova, K.A. (2009). Fanfikshn: literaturnyi fenomen kontsa XX - nachala XXI veka (tvorchestvo poklonnikov J.K. Rouling) [Fanfiction: the literature phenomenon of the end of the XX the beginning of the XXI centuries (works of J.K. Rowling's admirers)]. Extended abstract of candidate's thesis. Kaliningrad [in Russian].

Sharifullin, S.B. (2013). Verbalno-ikonicheskie teksty v sovremennoy muzykalnoy kommunikatsii [Verbal-iconic texts in modern musical communication]. Extended abstract of candidate's thesis. Krasnoiarsk [in Russian].

Eko, U. (1996). Dva tipa interpretatsii [Two types of interpretation]. Novoe literaturnoe obozrenie - New literary review, 21, 10-21 [in Russian].

Arnheim, R. (1966). Towards a Psychology of Art. Collected Essays. Los Angeles : University of California.

Bartlett, F. (1995). Remembering: A Study in Experimental and Social Psychology. Cambridge : The University Press. https://doi.org/10.1017/CBO9780511759185 
Вторинний мультимодальний дискурс сучасної англомовної...

Bortolussi, M., \& Dixon, P. (2003). Pscyhonarratology. Foundations for the Empirical Study of Literary Response. Cambridge : CUP.

Chan, T.K.S., Wong, S.W.L., Wong, A.M.Y., et al. (2018). The Influence of Presentation Format of Story on Narrative Production in Chinese Children Learning English-as-a-Second-Language: A Comparison Between Graphic Novel, Illustration Book and Text. Journal of Psycholinguistic Research, 1-22. https:// doi.org/10.1007/s10936-018-9600-9

Daly, A., \& Unsworth, L. (2011). Analysis and comprehension of multimodal texts. Australian Journal of Language and Literacy, 34(1), 61-80.

Delwiche, A. (2012). The Participatory Cultures Handbook. New York : Routledge. https://doi.org/10.4324/9780203117927

Eco, U. (1992). Interpretation and Overinterpretation. Cambridge : Cambridge University Press. https://doi.org/10.1017/CBO9780511627408

Eco, U. (1990). Unlimited Semiosis and Drift: Pragmaticism vs. «Pragmatism». The Limits of Interpretation (Advances in Semiotics), (pp. 22-43). Bloomington; Indianapolis : Indiana University Press.

Forceville, C., \& Urios-Aparisi, E. (2009). Multimodal Metaphor. Berlin : Mouton de Gruyter. https://doi.org/10.1515/9783110215366

Gibson, J.J. (1951). The perception of the visual world. Boston : Houghton Mifflin.

Jewitt, C., Bezemer, J., \& O’Halloran, K.L. (2016). Introducing multimodality. London \& New York : Routledge.

Iedema, R. (2007). Multimodality, resemiotization: extending the analysis of discourse as multi-semiotic practice. Visual Communication, 2(1), 29-57. https://doi. org/10.1177/1470357203002001751

Jenkins, H. (2006). Convergence culture: Where old and new media collide. New York and London : NYU press.

Kress, G.R. (2010). Multimodality. A Social Semiotic Approach to Contemporary Communication. London and New York : Routledge.

Kress, G.R., \& Leeuwen, T. van (2001). Multimodal Discourse. Bloomsbury Academic.

Kress, G.R., \& Leeuwen, T. van (2006). Reading Images: The Grammar of Visual Design. London : Routledge. https://doi.org/10.4324/9780203619728

Lakoff, G., \& Johnson, M. (2003). Metaphors We Live by. Chicago : University of Chicago Press. https://doi.org/10.7208/chicago/9780226470993.001.0001

Leeuwen, T. van (2004). Introducing Social Semiotics: An Introductory Textbook. London : Routledge. https://doi.org/10.4324/9780203647028

Nicoladis, E., Marentette, P., \& Navarro, S. (2016). Gesture Frequency Linked Primarily to Story Length in 4-10-Year Old Children's Stories. Journal of Psycholinguistic Research, 45(2), 189-204. https://doi.org/10.1007/s10936-0149342-2

Norman, D.A. (1972). Memory, Knowledge and Answering of Questions. Contemporary Issues in Cognitive Psychology. The Loyola Symposium. San Diego : University of California.

O’Halloran, K.L., \& Smith, B. (2011). Multimodal Studies: An Emerging Research Field. Multimodal Studies. Exploring Issues and Domain. (pp. 1-16). NY, Abington.

Reinwein, J. (2012). Does the Modality Effect Exist? and if So, Which Modality Effect? Journal of Psycholinguistic Research, 41(1), 1-32. https://doi.org/10.1007/ s10936-011-9180-4 
Secondary Multimodal Discourse of the Modern English Mass...

\section{АНОТАЦІЯ}

Статтю присвячено психолінгвістичним особливостям вторинного мультимодального дискурсу сучасної англомовної масової культури як лінгвосоціо-культурного френомену і типу комунікації з характерним контекстом комунікування. У представленому дослідженні вперше і вельми обгрунтовано визначено роль і місце вторинного типу дискурсу як феномену культури конвергенції у сучасній англомовній молодіжній субкультурі.

Шляхом диференціації таких суміжних понять, як «молодіжна субкультура» та «інтерпретативна спільнота» доведено, що останнє постає структурним елементом фанатської субкультури, і разом вони моделюють середовище аранжування вторинних текстопросторів. Наголошено на тому, що інтерпретативні спільноти утворюються на базі великих трансмедійних проектів, де розповідь вибудовується таким чином, аби донести до реципієнта світ або історію проекту з різних сторін і в різних формах.

Зазначено, що платформи для розвитку i поширення проекту не обов'язково мають бути виключно технічними засобами створення $i$ передавання інфрормації, адже трансмедійний проект може охоплювати певне літературне джерело, серіал, комп'ютерну гру, а також різну супутню продукцію, що так чи інакще робить свій внесок у розкриття суцільної історії. Саме тому, подану психолінгвістичну розвідку здійснено на об'ємному фрактологічному матеріалі - Всесвіті Marvel, елементи якого розподілені між різними платформами і разом створюють цілісний сюжетнокомпозиційний простір.

За результатами сочіолінгвістичного експерименту (анкетування носіїв англійської мови, загальною кількістю 100 осіб) встановлено, що неодмінною умовою трансмедійної розповіді всесвіту Marvel $\epsilon$ самостійність кожної окремої платформи. Сказане підтверджується статистичними даними, зокрема за результатами оnline-анкетування встановлено, що лише 15\% респондентів ознайомлено з тією частиною Всесвіту, яку репрезентовано у коміксах; 80\% опитуваних переконанані, що саме кінофрільми є точкою входу у Всесвіт і тому сприймаються як самостійні твори; і лише 5\% респондентів висловили невпевненність щодо первинності тієї чи іншої платформи.

Визначено, що саме завдяки трансмедійній розповіді та культурі співучасті, як ключових рис культури конвергенції, реципієнти таких маштабних проектів втрачають статус пасивних споживачів $i$ в межах інтерпретативних спільнот стають продуцентами нового медіа-контенту. Таким чином, психолінгвістичний механізм аранжування вторинних текстопросторів сучасної англомовної маскультури ідентифіковано через такі домінанті ознаки нової культурної парадигми, як: активний розвиток культури співучасті, інтертекстуальність, мультимодальність і трансмедійність.

Зроблено висновок, що у соціодискурсному просторі молодінної субкультури будь-яка ідея, зображення, сюжет або персонаж тощо, запозичені реципієнтами із культового текстопростору, конвертуються ними жу різноманітні медіаформати і поширюються по всім доступним платформам, створюючи єдиний і неподільний вторинний мультимодальний текстопростір. 
Вторинний мультимодальний дискурс сучасноӥ англомовної...

Ключові слова: дискурс, мультимодальність, текст, масова культура, медіаконвергенція, культура співучасті, трансмедійна розповідь.

Кузнецова Мария. Вторичный мультимодальный дискурс современной англоязычной масскультуры как феномен культуры конвергенции

\section{АННОТАЦИЯ}

Статья посвящена психолингвистическим особенностям вторичного мультимодального дискурса современной англоязычной массовой культуры как лингво-социо-культурного феномена и типа коммуникации с характерным контекстом. В представленном исследовании впервые и весьма обоснованно определены роль и место вторичного типа дискурса как феномена культуры конвергенции в современной англоязычной молодежной субкультуре.

Путем дифреренциации таких смежных понятий, как «молодежная субкультура» и "интерпретативное сообщество» доказано, что последнее является структурным элементом франатской субкультуры, и вместе они моделируют среду ранжирования вторичных текстопространств. Отмечено, что интерпретативные сообщества образуются на базе крупных трансмедийных проектов, где повествование выстраивается таким образом, чтобы донести до реципиента мир или историю проекта с разных сторон и в разных формах.

Отмечено, что платформы для развития и распространения проекта не должны быть исключительно техническими средствами создания и передачи информации, поскольку трансмедийный проект может включать в себя определенный литературный источник, сериал, компьютерную игру, а также различную сопутствующую продукцию, которая так или иначе делает свой вклад в раскрытие общей истории. Именно поэтому, представленное психолингвистическое исследование осуществлено на объемном фактологическом материале - Вселенной Marvel, элементы которой распределены между различными платорормами и вместе создают целостное сюжетно-композиционное пространство.

Согласно результатам социолингвистического эксперимента (анкетирование носителей английского языка, общим количеством 100 человек) установлено, что непременным условием трансмедийного повествования Вселенной Marvel является самостоятельность каждой отдельной платформы. Сказанное подтверждается статистическими данными, в частности в результате online-анкетирования установлено, что только 15\% респондентов ознакомлены с той частью Вселенной, которая представлена в комиксах; 80\% опрошенных убеждены, что именно кинофильмы являются точкой входа во Вселенную и потому воспринимаются как самостоятельные произведения; и лишь 5\% респондентов выразили неуверенность в первичности той или иной платформы.

Установлено, что именно благодаря трансмедийному повествованию и культуре соучастия, как ключевых особенностей культуры конвергенции, 
Secondary Multimodal Discourse of the Modern English Mass...

реципиенты таких маситабных проектов теряют статус пассивных потребителей и в пределах интерпретативных сообществ становятся продуцентами нового медиа-контента. Таким образом, психолингвистический механизм ранжирования вторичных текстопространств современной англоязычной массовой культуры идентифицировано через такие доминантные признаки новой культурной парадигмы, как: активное развитие культуры соучастия, интертекстуальность, мультимодальность и трансмедийность.

Сделан вывод, что в сочиодискурсном пространстве молодежной субкультуры любая идея, изображение, сюжет или персонаж, заимствованные реципиентами из культового текстопространства, конвертируются ими же в различные медиарорматы и распространяются по всем доступным платформам, образуя единое и неделимое вторичное мультимодальное текстопространство.

Ключевые слова: дискурс, мультимодальность, текст, массовая культура, медиаконвергенция, культура соучастия, трансмедийное повествование. 